\title{
BMJ Open Reporting of conflicts of interest in oral presentations at medical conferences: a delegate-based prospective observational study
}

\author{
Andrew Grey, ${ }^{1}$ Alison Avenell, ${ }^{2}$ Nicola Dalbeth, ${ }^{1}$ Fiona Stewart, ${ }^{2}$ Mark J Bolland ${ }^{1}$
}

To cite: Grey A, Avenell A, Dalbeth N, et al. Reporting of conflicts of interest in oral presentations at medical conferences: a delegate-based prospective observational study. BMJ Open 2017;7:e017019. doi:10.1136/ bmjopen-2017-017019

- Prepublication history and additional material for this paper are available online. To view please visit the journal (http:// dx.doi.org/10.1136/bmjopen2017-017019).

Received 27 March 2017 Revised 27 June 2017 Accepted 2 August 2017

CrossMark

${ }^{1}$ Department of Medicine, University of Auckland, Auckland, New Zealand

${ }^{2}$ Health Services Research Unit, University of Aberdeen Foresterhill, Scotland

Correspondence to Dr Andrew Grey; a.grey@auckland.ac.nz

\section{ABSTRACT}

Objective To assess the prevalence, location, presentation and consistency of conflict of interest statements in oral presentations at medical conferences

Design Prospective, delegate-based observational study Sample 201 oral presentations at 5 medical conferences in 2016

Main outcome measures Presence of a conflict of interest statement, its location within the presentation and its duration of display. Concordance between conflict of interest disclosures in oral presentations and written abstracts or meeting speaker information

Results Conflict of interest statements were present in $143 / 201(71 \%)$ presentations (range for conferences $26 \%-100 \%) .118$ of the 141 evaluable statements (84\%) were reported on a specific slide. Slides containing conflict of interest statements were displayed for a median (IQR) $2 \mathrm{~s}(1-5)$, range for conferences $1.25-7.5 \mathrm{~s}$. Duration of display was shorter when the slide contained only the conflict of interest statement, $2 \mathrm{~s}(1-3.5)$, than when it contained other information, $8 \mathrm{~s}(3-17)$, but was not affected by type of presentation or whether a conflict of interest was disclosed. When a conflict of interest was disclosed, 27/84 (32\%) presenters discussed an aspect of it. Discordance between the presence of a conflict of interest disclosure in the oral presentation and written formats occurred for $22 \%$ of presentations.

Conclusion In oral presentations at the medical conferences we assessed, conflict of interest statements were often missing, displayed too briefly to be read and understood, or not discussed/explained by the presenter. They were sometimes discordant with statements in the corresponding written formats. Conference delegates' ability to assess the objectivity and quality of the information in oral presentations may therefore have been diminished.

\section{INTRODUCTION}

Conflicts of interest (COIs) can compromise the integrity and objectivity of professional opinions, distort the interpretation of clinical research and erode public trust. ${ }^{1}$ Disclosure of COIs is widely promoted within academia, regarded as 'an essential, though limited' step in addressing the issue of potential bias. ${ }^{2}$
Strengths and limitations of this study

- An analysis of conflict of interest reporting at medical conferences in which data collection was undertaken in 'real-time' by delegate investigators.

- Conferences sampled spanned five medical disciplines, but may not be generalisable to all disciplines.

- The sample of conferences and presentations was determined pragmatically, based on the investigators' academic interests, not randomly selected.

- The study methodology did not permit an analysis of content of conflict of interest disclosure.

It permits the recipients of medical research findings and educational presentations to consider the potential for the competing interest(s) to influence the content and tone of the presentation.

Medical conferences are common, highly influential vehicles for informing and educating health practitioners: as many as 100000 may be held worldwide annually. ${ }^{3}$ Attendance contributes substantially to continuing medical education for many delegates. Oral presentations attract large audiences, and giving an oral presentation confers academic prestige. Commercial interest and involvement in medical conferences is strong, leading to concerns that such entities may have undue influence over programme content and faculty. ${ }^{34}$ In this setting, clear disclosure of COIs of presenters is important.

To date, limited research has been conducted on disclosure of COIs by speakers at medical conferences. In two disciplines, orthopaedics and oncology, COI disclosure was inconsistent ${ }^{5}$ and fleeting. ${ }^{6}$ We evaluated the prevalence, duration, presentation and consistency of COI disclosure in oral presentations at two international and three national conferences we attended in 2016. 
Our study was designed to evaluate these outcomes in 'real-time' from a delegate's perspective.

\section{METHODS}

\section{Medical conferences}

Four investigators conducted the assessments at five conferences in 2016: the US Endocrine Society (AG), the American College of Rheumatology (ND), the UK Continence Society (FS), the UK Congress on Obesity (AA), and Heart UK (AA). Our sample of conferences was pragmatic, being determined by our clinical or academic interests. Session attendance was also determined by investigators' interests, but all oral presentations attended were evaluated. Two conferences, those convened by the US Endocrine Society and the American College of Rheumatology, provided speakers with instructions about both the requirement for COI disclosure and its location within the presentation, the others did not. At one conference, the American College of Rheumatology, a meeting official screened presentations on site for the presence of a COI statement. Presentations were categorised as review or plenary $(\geq 30 \mathrm{~min})$, original research standard (10-15 min) or short (3 min), or other.

\section{Data collection}

Our study was conducted in real time. A single investigator gathered data at each conference. At each oral presentation assessed, the investigator sat with a clear, unobstructed view of the projection screen, and in a location at which the presentation was clearly audible, and completed a standardised spreadsheet (see online supplementary appendix).

\section{Outcomes}

Main outcomes were the presence of a COI statement, its location within the presentation and its duration of display. Duration of display of the COI was estimated by the sotto voce conversational recital of 'one elephant, two elephant...' for the duration of the display, where each 'elephant' approximates $1 \mathrm{s.}^{7}$

For each presentation, we also extracted COI information from the written abstract or speaker information in the conference programme, if either was available.

We recorded whether each presenter specifically discussed any aspect of a COI disclosure. If a presenter simply stated 'These are my disclosures/conflicts of interest', we did not code it as discussing the COI. We recorded whether the tone adopted to discuss a COI was serious or jokey/dismissive, as a subjective observation. We recorded examples of noteworthy terminology used by presenters in discussing COI disclosures.

\section{Statistics}

The composition and size of our sample of presentations were pragmatically determined by the structure of the contributing conferences and the interests of the delegate investigators. We report descriptive statistics as proportions or median (IQR). Comparisons between groups were made using the Mann-Whitney U test.

\section{Patient involvement}

Patients were not involved in the design or conduct of this study.

Because ours was an observational study in public where participants are not identified, ethical approval was not required.

\section{RESULTS}

We evaluated 201 presentations - 79 reviews, 119 original research (93 standard, 26 short) and 3 patient perspectives (table 1). One hundred and forty-three presentations $(71 \%)$ included a COI statement (range for conferences 26\%-100\%). For two presentations (one American College of Rheumatology, one UK Continence Society), it was not recorded whether a COI was disclosed. For three presentations (one US Endocrine Society, one UK Continence Society, one UK Congress on Obesity), duration of display of the COI statement was not recorded. Among the 141 evaluable presentations that included a COI statement, $84(60 \%)$ disclosed at least $1 \mathrm{COI}$ and $118(84 \%)$ reported the COI on a slide that only contained the COI (range for conferences 45\%-100\%).

\section{Disclosure of COls in oral presentations}

Figure 1 shows the duration of display of slides containing the COI statements. Overall, the median (IQR) duration of display of slides containing the COI statements was $2 \mathrm{~s}$ $(1-5)$. The median duration of display varied from $1.25 \mathrm{~s}$ to $7.5 \mathrm{~s}$ at individual conferences. Figure 2 shows the relationships between duration of display and three potential modifiers. Duration of display of the COI statement was shorter when the statement was on a specific slide, $2 \mathrm{~s}(1-3.5), \mathrm{n}=117$, than when it was on a slide containing other information, $8 \mathrm{~s}(3-17), \mathrm{n}=23, \mathrm{p}<0.0001$. It was similar in the presentations that disclosed at least one COI, 2s (1-6), $n=83$, and the presentations that disclosed no COI, 2s (1-4), $\mathrm{n}=55, \mathrm{p}=0.13$. It was similar in review/ plenary presentations, $2 \mathrm{~s}(1-5.3), \mathrm{n}=50$, and in other presentations, $2 \mathrm{~s}(1-5.3), \mathrm{n}=90, \mathrm{p}=0.42$.

Because of the very brief duration of display of most of the COI statements, we were rarely able to accurately count the number of individual COIs disclosed, or to discern their nature or relevance. Neither were our delegate investigators able to reliably ascertain whether COI statements referred to only the presenter or to the presenter and coauthors. In 27/84 (32\%) presentations that contained a COI statement and disclosed at least one COI, the speaker explicitly discussed an aspect of it. When such an explicit discussion was undertaken, its tone was dismissive or jokey in 9/27 (33\%) of instances (box).

Comparison of COI statements in oral and written formats Table 2 shows data on the relationships between COI statements in oral presentations and their corresponding 
Table 1 Characteristics of conferences, oral presentations and COI statements

\begin{tabular}{|c|c|c|c|c|c|}
\hline Conference & $\begin{array}{l}\text { COI disclosure } \\
\text { guidance provided }\end{array}$ & $\begin{array}{l}\text { Presentations } \\
\text { assessed } \\
\mathbf{n}\end{array}$ & $\begin{array}{l}\text { COI statement } \\
\text { included } \\
\mathrm{n} / \mathrm{n}(\%)\end{array}$ & $\begin{array}{l}\text { COI statement on } \\
\text { its own slide } \\
\mathrm{n} / \mathrm{n}(\%)\end{array}$ & $\begin{array}{l}\text { At least one COI } \\
\text { disclosed } \\
\mathrm{n} / \mathrm{n}(\%)\end{array}$ \\
\hline $\begin{array}{l}\text { US Endocrine } \\
\text { Society }\end{array}$ & Yes* $^{*}$ & 64 & $54 / 64$ (84\%) & $51 / 54 †(94 \%)$ & $33 / 54(61 \%)$ \\
\hline $\begin{array}{l}\text { American College of } \\
\text { Rheumatology }\end{array}$ & Yes $^{*} \ddagger$ & 45 & $45 / 45$ (100\%) & 45/45 (100\%) & $26 / 44 \S(59 \%)$ \\
\hline $\begin{array}{l}\text { UK Congress on } \\
\text { Obesity }\end{array}$ & No & 26 & $7 / 26(27 \%)$ & 4/79 (57\%) & $7 / 7$ (100\%) \\
\hline Heart UK & No & 23 & $6 / 23(26 \%)$ & 4/6ๆ (67\%) & $6 / 6(100 \%)$ \\
\hline Total & & 201 & 143/201 (71\%) & $118 / 143(83 \%)$ & $84 / 141(60 \%)$ \\
\hline
\end{tabular}

${ }^{*} \mathrm{COI}$ statement should be on second slide of presentation.

†Remaining $\mathrm{COI}$ statements were on title slides.

¥Meeting representative checked presentations for compliance with presence and location of COI statement.

$\S$ Not recorded for one presentation.

IRemaining $\mathrm{COI}$ statements were on title slide or conclusion slide.

$\mathrm{COI}$, conflict of interest.

written formats (abstracts or meeting speaker information). For 192/201 presentations, there was a corresponding written abstract and/or speaker information in either the online or hard copy conference programme. For three conferences, the UK Continence Society, the UK Congress on Obesity, and Heart UK, no COI statements were available for any of the meeting abstracts $(\mathrm{n}=93)$ in their written formats. Therefore, in only 99 of $192(52 \%)$ presentations was there a COI statement in both oral and written formats. For these 99 presentations, we found discordance for the presence of a COI disclosure between the oral and written formats in 22 cases (22\%) (figure 3). A COI disclosure was found in the oral but not the written format in 17 of the 22 discordant cases, and in the written but not the oral format in 5 of the 22 discordant cases. The proportions of presentations discordant for the presence of a COI disclosure and of discordance attributable to absence of a COI disclosure in each format were similar at each evaluable conference.

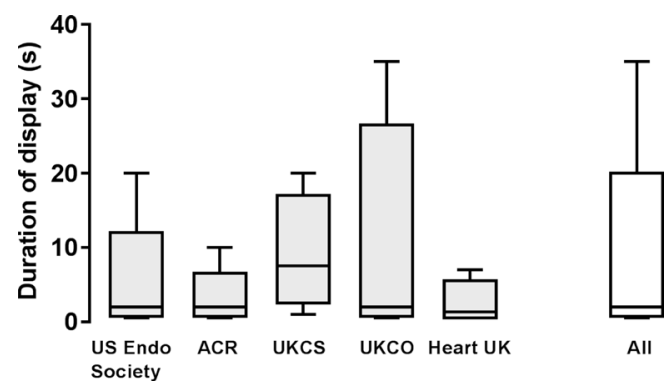

Figure 1 Duration of display of slides containing conflict of interest statements in oral presentations at medical conferences. Data are median, IQR and range. ACR, American College of Rheumatology; UKCO, UK Congress on Obesity; UKCS, UK Continence Society; US Endo Society, US Endocrine Society.

\section{DISCUSSION}

\section{Main findings}

In our sample, $29 \%$ of oral presentations at medical conferences did not include a COI statement, and therefore did not comply with recommendations that COI disclosure be undertaken in academic discourse. ${ }^{2}$ When present, COI statements were often displayed too briefly to read, let alone understand. Although the duration of display of a COI statement might be influenced by time constraints for the presentation, it was similarly brief in

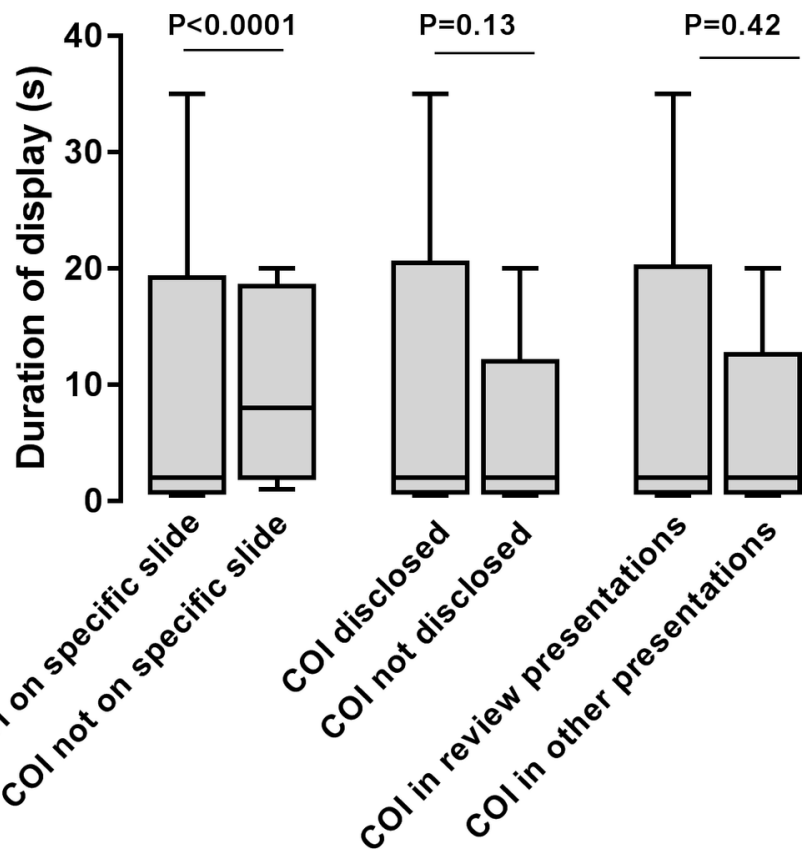

Figure 2 Duration of display of slides containing conflict of interest statements in oral presentations at medical conferences. Data are median, IQR and range. COI, conflict of interest. 
Box 1 Examples of dismissive or jokey approaches to discussing conflict of interest disclosure

'[Company X] have funded me to do disease state talks and the creativity of the company has been appreciated.'

'Here are my potential conflicts of interest: I've been very bad (pointing to list of commercial conflicts) and very lucky (pointing to grant funding).'

'These are my disclosures, none are particularly relevant.' № explanatory statement.

'Here are my conflicts. If you don't like them, I have more.'

'I work with a lot of companies.' Speaker claimed requirement for academic-industry 'collaboration' to 'help our patients', did not explain nature of multiple listed conflicts of interest.

'I'll come back to these later,' but did not do so.

longer review presentations and shorter original research presentations. The longer duration of display of COI statements when they were presented on slides that contained other information suggests that the other information was responsible for the longer display. Speakers seldom discussed or explained any aspect of their disclosed COIs, and sometimes adopted a dismissive or frivolous tone when doing so. COI statements were not present in $48 \%$ of the written formats corresponding to oral presentations. When COI statements were present in both oral presentations and the corresponding written formats, discordance in the presence of a COI disclosure between oral and written formats occurred in $22 \%$ of cases.

Table $2 \mathrm{COI}$ and disclosures in oral presentations and meeting programme*

\begin{tabular}{lll}
\hline & $\begin{array}{l}\text { Oral presentations } \\
\text { with } \\
\text { corresponding } \\
\text { written abstract } \\
\text { or speaker } \\
\text { information } \\
\text { N }\end{array}$ & $\begin{array}{l}\text { COI statement } \\
\text { present in both } \\
\text { oral presentation } \\
\text { and written } \\
\text { abstract } \\
\text { or speaker } \\
\text { information } \\
\text { N/N (\%) }\end{array}$ \\
\hline $\begin{array}{l}\text { Conference } \\
\text { US Endocrine }\end{array}$ & 64 & $54 / 64(84 \%)$ \\
$\begin{array}{l}\text { Society } \\
\text { American College } \\
\text { of Rheumatology }\end{array}$ & 45 & $45 / 45(100 \%)$ \\
$\begin{array}{l}\text { UK Continence } \\
\text { Society }\end{array}$ & 43 & $0 / 43(0 \%)$ \\
\hline $\begin{array}{l}\text { UK Congress on } \\
\text { Obesity }\end{array}$ & $19 \dagger$ & $0 / 19(0 \%)$ \\
\hline Heart UK & $21 \mp$ & $0 / 21(0 \%)$ \\
\hline Total & 192 & $\mathbf{9 9 / 1 9 2 ( 5 2 \% )}$ \\
\hline
\end{tabular}

*Written presentation abstract or speaker faculty information. †For seven presentations, neither written abstract nor speaker information was available.

†For two presentations, neither written abstract nor speaker information was available.

$\mathrm{COI}$, conflict of interest.
COI disclosure in written format only

COI disclosure in oral format only

COI disclosures in both formats

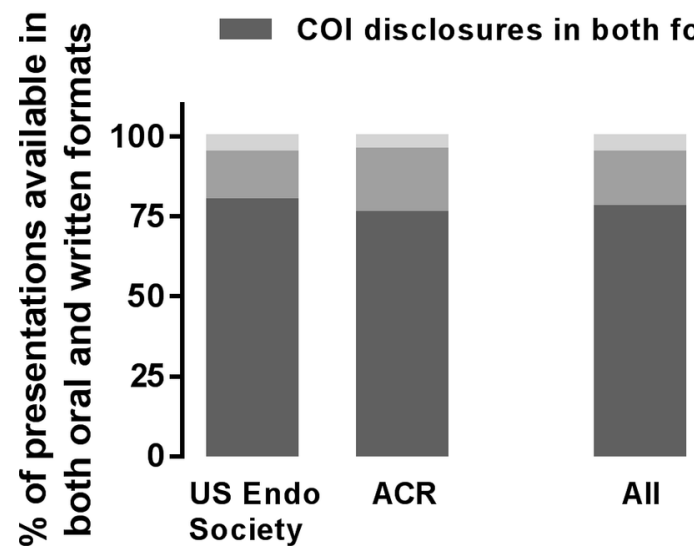

Figure 3 Discordance in the presence of COI statements between oral presentations at medical conferences and the corresponding written formats (written abstract or speaker information). No oral presentations at the other conferences had conflict of interest statements present in both oral presentations and the corresponding written formats. ACR, American College of Rheumatology; COI, conflict of interest; US Endo Society, US Endocrine Society.

\section{Limitations}

Although our study assessed presentations at meetings spanning five disciplines, our results might not apply to other medical specialities. Collecting data in real time is both a strength, mimicking as closely as possible the experiences of conference delegates, and a limitation, because it precludes analysis of the nature and relevance of the COI. Data were collected for each oral presentation by a single investigator. We did not randomly select the presentations assessed, instead taking a pragmatic approach which is likely to approximate the behaviour of most conference delegates.

\section{Context}

Our study suggests delegates at medical conferences may be unable to accurately assess the potential influence of COI on the content and conclusions of oral presentations. This could occur because COI statements may frequently be absent, displayed too briefly to be read or not discussed in the context of the material being presented. Delegates who wish to obtain information about COIs relevant to oral presentations from the corresponding written formats may be thwarted by their absence from the latter, or misled because of inaccurate or discordant disclosures. Failure to achieve adequate communication of information about COIs might impair the delegates' ability to assess the value and quality of the information contained in the presentations. A systematic review reported that patients, physicians and participants in clinical research all considered that financial COIs compromised the quality of clinical care and research. ${ }^{8}$

We found that rates of inclusion of COI statements in presentations varied among conferences: higher rates were achieved when conference organisers provided 
specific instructions and/or pursued policies to vet presentations for COI statements. However, these policies did not necessarily enhance the delegates' knowledge or understanding of the COIs, because the duration of display of the COI statements in presentations at those conferences was as brief as that for the COI statements in the presentations at the conferences without specific policies designed to promote inclusion of COI statements. Among conferences that did not provide instructions about COI statements, the UK Continence Society meeting achieved a higher rate of inclusion of statements. The reason for this is uncertain, but it might reflect heightened awareness of COIs arising from controversy about financial COIs over transvaginal mesh devices (personal communication, Emeritus Professor Cathryn Glazener).

We identified few studies similar to ours. However, Endo et al reported that only $72 \%$ of oral presentations at a dermatology conference included a COI statement, even after several strategies were applied to remind presenters of the requirement to do so. ${ }^{9}$ In addition, two studies reported display times of 3 and $5 \mathrm{~s}$, respectively, for slides containing COI information at orthopaedic and oncology meetings, respectively. ${ }^{6}{ }^{10}$ Finally, 9\% of presenters who gave oral presentations at each of two conferences on arthroplasty in the same calendar year disclosed financial COIs at one meeting but not the other. ${ }^{11}$ Each of these results is broadly consistent with our findings, and suggests that the results we report apply generally across conferences in medical disciplines other than those we assessed.

\section{CONCLUSIONS AND IMPLICATIONS}

Our study suggests that management of COI at medical meetings may be suboptimal. To avoid paying lip service to COIs in conference presentations, improvements could be made in several areas and both conference organisers and presenters can contribute. Disclosure statements should be required and their presence audited. Efforts to standardise the content and focus of COI statements, such as those initiated by the Institute of Medicine, ${ }^{12}$ should be supported and applied by conference organisers. COI statements by presenters should be displayed long enough to permit understanding, and their relevance adequately discussed. Innovative strategies such as displaying COI statements during question time, or having the session chairperson include a COI statement as part of the introduction of the presentation, could be trialled. Finally, presenters should explain any discordance between the contents of disclosures in oral and written formats.

Contributors All authors are academics with a research interest in translation of evidence into clinical practice. AG, AA and MJB conceived and designed the study. $A G, A A, N D$ and $F S$ collected the data. AG performed the statistical analyses. AG wrote the draft manuscript. All authors reviewed and approved the final submission. $A G$ is the guarantor of the paper.
Funding The study was funded by the Health Research Council (HRC) of New Zealand. The Health Services Research Unit at the University of Aberdeen is funded by the Chief Scientist Office of the Scottish Government Health and Social Care Directorates. The funders had no role in the design and conduct of the study; collection, management, analysis and interpretation of the data; and preparation, review or approval of the manuscript.

Competing interests All authors have completed the ICMJE unified disclosure form and competing interest form at www.icmje.org/coi_disclosure.pdf (available upon request from the corresponding author). None of the authors were involved in any aspect of the organisation of the conference(s) they attended. AG is a shareholder in Auckland Bone Density, a company that provides bone mineral density measurements. ND discloses consulting fees, speaker fees or grants from Takeda, Menarini, Teijin, Pfizer, Ardea Biosciences, AstraZeneca, Crealta, Fonterra, Cymabay and Abbvie. FS gave an oral presentation at the conference she attended. Her attendance was funded by the Cochrane Incontinence Group, the largest single funder of which is The National Institute for Health Research. AA and MJB have no financial conflict to interest to declare. AG and MJB have coauthored publications on conflicts of interest in the interpretation and dissemination of clinical research findings. All authors consider that conflicts of interest are potentially important in the interpretation and dissemination of research findings.

Provenance and peer review Not commissioned; externally peer reviewed.

Data sharing statement Data available upon request for academic researchers.

Open Access This is an Open Access article distributed in accordance with the Creative Commons Attribution Non Commercial (CC BY-NC 4.0) license, which permits others to distribute, remix, adapt, build upon this work non-commercially, and license their derivative works on different terms, provided the original work is properly cited and the use is non-commercial. See: http://creativecommons.org/ licenses/by-nc/4.0/

(c) Article author(s) (or their employer(s) unless otherwise stated in the text of the article) 2017. All rights reserved. No commercial use is permitted unless otherwise expressly granted.

\section{REFERENCES}

1. Dunn AG, Coiera E, Mandl KD, et al. Conflict of interest disclosure in biomedical research: A review of current practices, biases, and the role of public registries in improving transparency. Res Integr Peer Rev 2016;1:1-8.

2. Institute of Medicine. Conflict of interest in medical research, education, and practice. $2009 \mathrm{http}: / /$ nationalacademies.org/hmd/ reports/2009/conflict-of-interest-in-medical-research-education-andpractice.aspx.

3. loannidis JP. Are medical conferences useful? And for whom? JAMA 2012;307:1257-8.

4. Rothman DJ, McDonald WJ, Berkowitz CD, et al. Professional medical associations and their relationships with industry: a proposal for controlling conflict of interest. JAMA 2009;301:1367-72.

5. Ju BL, Miller CP, Whang PG, et al. Quantifying the variability of financial disclosure information reported by authors presenting at annual spine conferences. Spine J 2011;11:1-8.

6. Boothby A, Wang R, Cetnar J, et al. Effect of the American Society of Clinical Oncology's conflict of interest policy on information overload . JAMA Oncol 2016;2:1653-4.

7. Appendix:Words used as placeholders to count seconds. Wiktionary https://en.wiktionary.org/wiki/Appendix:Words_used_as_ placeholders_to_count_seconds (accessed Feb 2017).

8. Licurse A, Barber E, Joffe S, et al. The impact of disclosing financial ties in research and clinical care: a systematic review. Arch Intern Med 2010;170:675-82.

9. Endo JO, Myers D, Stratman EJ. Conflict of interest and disclosure: Analysis of American Academy of Dermatology Annual Meetings. $J$ Am Acad Dermatol 2012;66:e20-e21.

10. Sassoon AA, Trousdale RT. Podium disclosures at the 2012 AAOS meeting: an exercise in going through the motions. J Bone Joint Surg Am 2013;95:e51.

11. Choo KJ, Yi PH, Burns R, et al. Variable reporting by authors presenting arthroplasty research at multiple annual conferences. $J$ Arthroplasty 2017;32:315-9.

12. Lichter AS, McKinney R. Toward a harmonized and centralized conflict of interest disclosure: progress from an IOM initiative. JAMA 2012;308:2093-4. 